\title{
Supernova mixing to reproduce isotopic ratios of presolar grains
}

\section{Takashi Yoshida*}

Division of Theoretical Astronomy, National Astronomical Observatory of Japan E-mail: takashi.yoshida@nao.ac.jp

Presolar grains are considered to have traces in their birth before the solar system formation in their isotopic and elemental features. Most of silicon carbide type X ( $\mathrm{SiC} \mathrm{X}$ ) and low density graphite grains show the excesses of ${ }^{12} \mathrm{C}$ and ${ }^{28} \mathrm{Si}$. These isotopic features suggest that $\mathrm{SiC} \mathrm{X}$ and low density graphite are originating from supernovae. On the other hand, elemental signatures of the grains suggest the grain formation in carbon-enriched materials, although the bulk composition of supernova ejecta is oxygen-rich. Therefore, the parent materials of the grains should have been formed by large-scale inhomogeneous mixing during supernova explosions to reproduce isotopic elemental signatures of presolar grains from supernovae. We investigate supernova mixtures reproducing isotopic ratios of individual single $\mathrm{SiC} \mathrm{X}$ and low density graphite grains. We consider seven-layer mixtures of supernova ejecta. We seek mixtures reproducing as many isotopic ratios as possible of each of the grains. Then, the mixtures reproducing five and six isotopic ratios of $\mathrm{SiC} \mathrm{X}$ grains and low density graphite grains are obtained, respectively. The mixtures are classified into three groups based on reproduced isotopic ratios. The main component of the mixtures is one of deep Ni-rich layer, outer $\mathrm{He} / \mathrm{C}$ layer, and $\mathrm{He} / \mathrm{N}$ layer. The $\mathrm{C} / \mathrm{O}$ ratios of most of the mixtures are larger than 1 . The ratios of $\mathrm{Fe} / \mathrm{C}$ and $\mathrm{Fe} / \mathrm{Si}$ are different between the mixtures corresponding to $\mathrm{SiC} \mathrm{X}$ and low density graphite grains.

10th Symposium on Nuclei in the Cosmos

July 27 - August 12008

Mackinac Island, Michigan, USA

\footnotetext{
${ }^{*}$ Speaker.
} 


\section{Introduction}

Most of silicon carbide type $\mathrm{X}(\mathrm{SiC} \mathrm{X})$ and low density graphite grains show excesses of ${ }^{12} \mathrm{C}$ and ${ }^{28} \mathrm{Si}$ in $\mathrm{C}$ and $\mathrm{Si}$ isotopic ratios, respectively (e.g., reviews in [1], 2]). Some of the grains have evidence for the original presence of short-lived nuclei ${ }^{44} \mathrm{Ti}[3]$. These isotopic signatures suggest that $\mathrm{SiC} \mathrm{X}$ and low density graphite are originating from supernovae. Recently, some oxide grains from supernovae have been found (e.g. [屯]). Silicate grains indicating the enrichment of ${ }^{18} \mathrm{O}$ and ${ }^{28} \mathrm{Si}$ were found recently, and these grains are new candidate of supernova originating grains [5].

Silicon carbide $\mathrm{X}$ and low density graphite grains are considered to have been formed in carbon-enriched materials [6]. This suggests that these grains should have been formed from the materials enriched in carbon and having ${ }^{28} \mathrm{Si}$ excesses. Massive stars form layered composition structure during the stellar evolution. A carbon-enriched layer is formed in outer region of the star but ${ }^{28} \mathrm{Si}$-enriched layer is formed in inner region. Further, stellar interior except $\mathrm{C} / \mathrm{O}$ and $\mathrm{He} / \mathrm{C}$ layers is enriched in oxygen rather than carbon, and the bulk composition is oxygen-rich. Therefore, the chemical composition of each layer and the bulk composition of supernova ejecta do not reproduce either isotopic or elemental signatures found in the grains. The original materials of the grains should have been formed by large-scale inhomogeneous mixing during supernova explosions to reproduce isotopic and elemental signatures of the grains.

Isotopic ratios of $\mathrm{SiC} \mathrm{X}$ and low density graphite grains have been compared with supernova mixtures [7, 8, 9]. The supernova ejecta were divided into seven zones. Then, the variations of isotopic ratios of supernova mixtures on the diagrams of two isotopic ratios were investigated varying the mixing ratios of supernova zones and assuming a $\mathrm{C} / \mathrm{O}$ ratio. The isotopic signatures for ${ }^{12} \mathrm{C} /{ }^{13} \mathrm{C}$, ${ }^{16} \mathrm{O} /{ }^{18} \mathrm{O},{ }^{30} \mathrm{Si} /{ }^{28} \mathrm{Si}$ and ${ }^{44} \mathrm{Ti}$ and ${ }^{41} \mathrm{Ca}$ observed in the grains were reproduced by supernova mixtures. However, how many isotopic ratios of individual single presolar grains are reproduced by supernova mixtures has not been clarified. In this study, we seek supernova mixtures reproducing as many as possible for individual single $\mathrm{SiC} \mathrm{X}$ and low density graphite grains. This investigation shows the mixing ratios and elemental compositions of the supernova mixtures reproducing isotopic ratios of the individual single grains. We investigate general features of the mixing ratios and elemental compositions of the supernova mixtures. Detailed results of this study are shown in [10].

\section{Supernova models and presolar grains from supernovae}

The chemical composition distributions of the supernova ejecta for 3.3, 4, 6, and $8 M_{\odot} \mathrm{He}$ star models, corresponding to $13,15,20$, and $25 M_{\odot}$ stars at the zero-age main sequence [9] are adopted. The supernova ejecta are divided into seven layers based on the main elemental distribution; the $\mathrm{Ni}, \mathrm{Si} / \mathrm{S}, \mathrm{O} / \mathrm{Si}, \mathrm{O} / \mathrm{Ne}, \mathrm{C} / \mathrm{O}$ or $\mathrm{O} / \mathrm{C}, \mathrm{He} / \mathrm{C}$, and $\mathrm{He} / \mathrm{N}$ layers. The mixtures indicating isotopic ratios with small difference from those of individual single grains are sought using $\chi^{2}$-evaluation. The $\chi^{2}$-value of a mixture for a grain is evaluated as a function of the mixing ratio of layer $a, x_{a}$.

$$
\chi^{2}=\sum_{\text {iso }} \frac{\left\{r_{\text {iso,mixture }}(\mathbf{x})-r_{\text {iso,grain }}\right\}^{2}}{\sigma_{\text {iso,grain }}^{2}},
$$

where $r_{\text {iso,mixture }}(\mathbf{x})$ is the "iso" isotopic ratios of the mixture with the mixing ratios $x_{a}, r_{\text {iso,grain }}$ and $\sigma_{\text {iso,grain }}$ are the measured "iso" isotopic ratio of the grain and its $\sigma$-value. The minimum $\chi^{2}$-value 

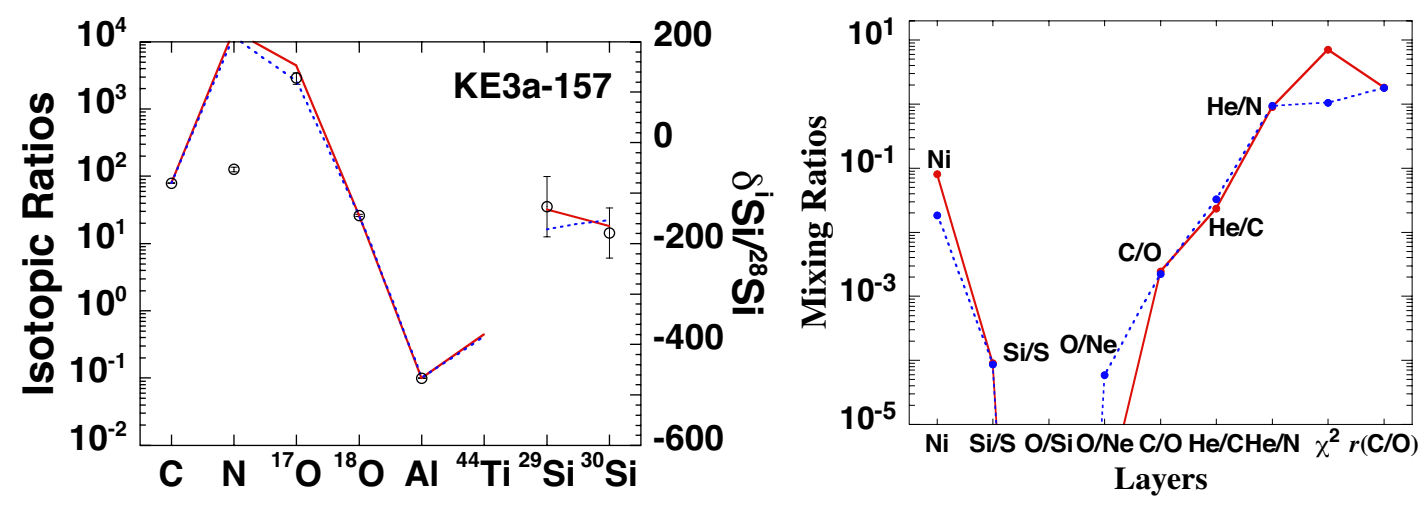

Figure 1: Left panel: Isotopic ratios of low density graphite grain KE3a-157 (open circles with error bars) and the mixtures of the $3.3 M_{\odot}$ (red solid line) and $4 M_{\odot}$ (blue dotted line) He star supernova models reproducing isotopic ratios of the grain. Right panel: The mixing ratios, $\chi^{2}$ values, and $\mathrm{C} / \mathrm{O}$ ratio $r(\mathrm{C} / \mathrm{O})$ of the mixtures of the $3.3 M_{\odot}$ (red solid line) and $4 M_{\odot}$ (blue dotted line) supernova models. $\delta^{i} \mathrm{Si} /{ }^{28} \mathrm{Si} \equiv$ $\left\{\left(N\left({ }^{i} \mathrm{Si}\right) / N\left({ }^{28} \mathrm{Si}\right)\right) /\left(N\left({ }^{i} \mathrm{Si}\right) / N\left({ }^{28} \mathrm{Si}\right)\right)_{\odot}-1\right\} \times 1000$.

with the constraints $0 \leq x_{a} \leq 1$ and $\sum_{a} x_{a}=1$ is sought using a minimization method with a genetic algorithm with floating-point representation [11]. When $N_{\text {iso }}$ isotopic ratios are compared and $\chi^{2}$ is smaller than $4 N_{\text {iso }}$, we consider that $N_{\text {iso }}$ isotopic ratios of the grain is reproduced by the mixture.

Supernova mixtures are compared to isotopic ratios of $6 \mathrm{SiC}$ type $\mathrm{X}$ grains [3, 8, 12] and 26 low density graphite grains [7]. For $\mathrm{SiC} \mathrm{X},{ }^{12} \mathrm{C} /{ }^{13} \mathrm{C},{ }^{14} \mathrm{~N} /{ }^{15} \mathrm{~N},{ }^{26} \mathrm{Al} /{ }^{27} \mathrm{Al},{ }^{29} \mathrm{Si} /{ }^{28} \mathrm{Si},{ }^{30} \mathrm{Si} /{ }^{28} \mathrm{Si}$, and ${ }^{44} \mathrm{Ti} /{ }^{48} \mathrm{Ti}$ are adopted. For graphite grains, ${ }^{12} \mathrm{C} /{ }^{13} \mathrm{C},{ }^{14} \mathrm{~N} /{ }^{15} \mathrm{~N},{ }^{16} \mathrm{O} /{ }^{17} \mathrm{O},{ }^{16} \mathrm{O} /{ }^{18} \mathrm{O},{ }^{26} \mathrm{Al} /{ }^{27} \mathrm{Al}$, ${ }^{29} \mathrm{Si} /{ }^{28} \mathrm{Si}$, and ${ }^{30} \mathrm{Si} /{ }^{28} \mathrm{Si}$ are compared. The ratio of ${ }^{44} \mathrm{Ti} /{ }^{48} \mathrm{Ti}$ is also compared for 3 graphite grains.

\section{Isotopic compositions and mixing ratios of supernova mixtures}

In this study, we obtained 13 mixtures reproducing 5 isotopic ratios of 3 individual $\mathrm{SiC} \mathrm{X}$ grains. We also found 49 mixtures reproducing 6 isotopic ratios of 20 individual low density graphite grains. Here we classify the obtained mixtures into 3 groups, i.e., Group C, Group N, and Group $\mathrm{CN}$, based on the reproduced isotopic ratios.

The mixtures of Group $\mathrm{C}$ reproduce $5(\mathrm{SiC} \mathrm{X})$ and 6 (graphite) isotopic ratios of the grains from supernovae except for ${ }^{14} \mathrm{~N} /{ }^{15} \mathrm{~N}$. Figure 1 shows six isotopic ratios, the mixing ratios, the $\chi^{2}$ values, and the $\mathrm{C} / \mathrm{O}$ ratios of two mixtures in Group $\mathrm{C}$ reproducing 6 isotopic ratios of low density graphite grain KE3a-157. The two mixtures well reproduce six isotopic ratios of KE3a-157. Only ${ }^{14} \mathrm{~N} /{ }^{15} \mathrm{~N}$ ratios of the mixtures show much larger than the ratio of the grain. The main component of the mixtures is the $\mathrm{He} / \mathrm{N}$ layer. The $\mathrm{Ni}$ and $\mathrm{He} / \mathrm{C}$ layers are included with smaller fractions. The $\mathrm{C} / \mathrm{O}$ ratios of these mixtures are 1.8 .

The above characteristics of the isotopic ratios and the mixing ratios are in common among the mixtures in Group C. The main component of the mixtures is the He/ $\mathrm{N}$ layer. This layer indicates large ${ }^{13} \mathrm{C}$ excess. The mixtures contain smaller fractions of $\mathrm{He} / \mathrm{C}$ and $\mathrm{Ni}$ layers. The He/C layer indicates ${ }^{18} \mathrm{O}$ excess. The Ni layer shows large ratios of ${ }^{26} \mathrm{Al} /{ }^{27} \mathrm{Al}$ and ${ }^{44} \mathrm{Ti} /{ }^{48} \mathrm{Ti}$. The He/N layer also indicates large ${ }^{14} \mathrm{~N}$ excess, so that these mixtures do not reproduce ${ }^{14} \mathrm{~N} /{ }^{15} \mathrm{~N}$ of the grains. 


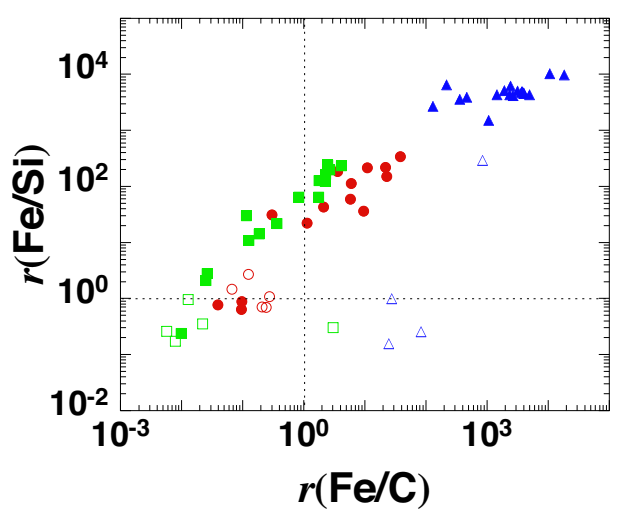

Figure 2: Elemental ratios $r(\mathrm{Fe} / \mathrm{C})$ and $r(\mathrm{Fe} / \mathrm{Si})$ of the mixtures reproducing isotopic ratios of presolar grains from supernovae. Circles, squares, and triangles correspond to the mixtures belonging to Group C, Group $\mathrm{N}$, and Group $\mathrm{CN}$, respectively. Open and closed symbols are the mixtures reproducing isotopic ratios of $\mathrm{SiC} \mathrm{X}$ and low density graphite grains.

The mixtures of Group $\mathrm{N}$ reproduce isotopic ratios except ${ }^{12} \mathrm{C} /{ }^{13} \mathrm{C}$. The main component of the mixtures is the He/C layer. The He/C layer indicates small ${ }^{14} \mathrm{~N} /{ }^{15} \mathrm{~N}$ ratio, so that it is appropriate for reproducing ${ }^{14} \mathrm{~N} /{ }^{15} \mathrm{~N}$ ratio to include the He/C layer. However, this layer also indicates large excess of ${ }^{12} \mathrm{C}$. Thus, these mixtures show very large ${ }^{12} \mathrm{C} /{ }^{13} \mathrm{C}$ ratio. Smaller fractions of the $\mathrm{Ni}$, $\mathrm{Si} / \mathrm{S}, \mathrm{O} / \mathrm{Ne}, \mathrm{C} / \mathrm{O}$, and $\mathrm{He} / \mathrm{N}$ are contained in these mixtures.

The mixtures of Group $\mathrm{CN}$ reproduce isotopic ratios including both of ${ }^{12} \mathrm{C} /{ }^{13} \mathrm{C}$ and ${ }^{14} \mathrm{~N} /{ }^{15} \mathrm{~N}$. However, one of ${ }^{26} \mathrm{Al} /{ }^{27} \mathrm{Al},{ }^{29} \mathrm{Si} /{ }^{28} \mathrm{Si},{ }^{30} \mathrm{Si} /{ }^{28} \mathrm{Si}$, and ${ }^{44} \mathrm{Ti} /{ }^{48} \mathrm{Ti}$ is not reproduced. The main component of the mixtures is the Ni layer. The Ni layer indicates small ${ }^{12} \mathrm{C} /{ }^{13} \mathrm{C}$ and ${ }^{14} \mathrm{~N} /{ }^{15} \mathrm{~N}$ although the mass fractions of $\mathrm{C}$ and $\mathrm{N}$ are small. Thus, this layer is favorable to reproduce ${ }^{12} \mathrm{C} /{ }^{13} \mathrm{C}$ and ${ }^{14} \mathrm{~N} /{ }^{15} \mathrm{~N}$ of the grains. The Ni layer also indicates large ${ }^{26} \mathrm{Al} /{ }^{27} \mathrm{Al}$ and ${ }^{44} \mathrm{Ti} /{ }^{48} \mathrm{Ti}$. Therefore, it is difficult to reproduce these isotopic ratios of the grains indicating small ${ }^{26} \mathrm{Al} /{ }^{27} \mathrm{Al}$ and ${ }^{44} \mathrm{Ti} /{ }^{48} \mathrm{Ti}$.

\section{Elemental signatures of supernova mixtures}

Elemental signatures are important for constraining the materials from which supernova originating grains have been formed. Some elemental signatures are expected to be obtained from the supernova mixtures evaluated in this study. Here we discuss the elemental ratios of $\mathrm{C} / \mathrm{O}, \mathrm{Fe} / \mathrm{C}$, and $\mathrm{Fe} / \mathrm{Si}$ in the mixtures.

As explained in introduction, the $\mathrm{C} / \mathrm{O}$ ratio is important for the grain formation. $\mathrm{SiC}$ and low density graphite grains should have been formed in carbon-enriched materials rather than oxygen [6]. Thus, we investigate the $\mathrm{C} / \mathrm{O}$ ratios of the supernova mixtures. Eight mixtures for $\mathrm{SiC} \mathrm{X}$ and 39 mixtures for graphite indicate the $\mathrm{C} / \mathrm{O}$ ratio between 1 and 2 . One mixture for $\mathrm{SiC} \mathrm{X}$ and eight mixtures for graphite show the $\mathrm{C} / \mathrm{O}$ ratio larger than 2 . So, we can say that most of the mixtures satisfy the grain formation condition. The mixtures of Group $\mathrm{CN}$ for $\mathrm{SiC} \mathrm{X}$ indicate the $\mathrm{C} / \mathrm{O}$ ratio much smaller than 1 . These mixtures do not satisfy the grain formation condition.

We also investigate the features of $\mathrm{Fe} / \mathrm{C}$ and $\mathrm{Fe} / \mathrm{Si}$. TiC subgrains have been found in low density graphite [13]. They are considered to have been formed as $(\mathrm{Fe}, \mathrm{Ni})_{2} \mathrm{Ti}$ in very $\mathrm{Fe}$-enriched 
zone at first, and they changed to $\mathrm{TiC}$ in the materials mixed with C-rich zone [14]. Figure 2 shows the relation between $r(\mathrm{Fe} / \mathrm{C})$ and $r(\mathrm{Fe} / \mathrm{Si})$ of the supernova mixtures. Most of the mixtures for $\mathrm{SiC}$ $\mathrm{X}$ are enriched in Si rather than $\mathrm{Fe}$. On the other hand, the most of the mixtures for low density graphite show the enrichment in $\mathrm{Fe}$ and $\mathrm{C}$. Furthermore, the mixtures of Groups $\mathrm{C}$ and $\mathrm{CN}$ indicate $r(\mathrm{Fe} / \mathrm{C})>1$. The mixtures of Group $\mathrm{CN}$ may be adequate for the formation of TiC subgrains.

\section{Summary}

In order to reproduce isotopic and elemental signatures of presolar grains from supernovae, it is important to consider large-scale inhomogeneous mixing in supernova ejecta. We investigated supernova mixtures reproducing as many isotopic ratios as possible of individual single $\mathrm{SiC}$ type $\mathrm{X}$ and low density graphite grains. The mixtures reproducing five and six isotopic ratios for $\mathrm{SiC}$ $\mathrm{X}$ grains and low density graphite grains, respectively, were obtained. The obtained mixtures were classified into Group C, Group N, and Group CN based on reproduced isotopic ratios. The main components of the mixtures in Group C, Group N, and Group $\mathrm{CN}$ are the $\mathrm{He} / \mathrm{N}, \mathrm{He} / \mathrm{C}$, and $\mathrm{Ni}$ layers, respectively. The dependence of the elemental ratios $\mathrm{C} / \mathrm{O}, \mathrm{Fe} / \mathrm{C}$, and $\mathrm{Fe} / \mathrm{Si}$ in the supernova mixtures were also investigated. Most of the mixtures indicate the $\mathrm{C} / \mathrm{O}$ ratio larger than 1 . On the other hand, the features of $\mathrm{Fe} / \mathrm{C}$ and $\mathrm{Fe} / \mathrm{Si}$ are different between the mixtures corresponding to $\mathrm{SiC}$ $\mathrm{X}$ and low density graphite. The mixtures for $\mathrm{SiC} \mathrm{X}$ are enriched in Si rather than Fe. Those for low density graphite show the enrichment of $\mathrm{Fe}$ and $\mathrm{C}$.

\section{References}

[1] D.D. Clayton \& L.R. Nittler, Ann. Rev. Astron. Astrophys. 42 (2004) 39.

[2] K. Lodders \& S. Amari, Chem. Erde Geochem. 65 (2005) 93.

[3] L.R. Nittler, S. Amari, E. Zinner, S.E. Woosley, \& R.S. Lewis, Astrophys. J. 462 (1996) L31.

[4] L.R. Nittler, C.M.O’D. Alexander, X. Gao, R.M. Walker, \& E. Zinner, Astrophys. J. 483 (1997) 475.

[5] C. Vollmer, P. Hoppe, \& F.E. Brenker, Astrophys. J. 684 (2008) 611.

[6] K. Lodders \& B. Fegrey,Jr., in AIP Conf. Proc. 402 (1997) 391.

[7] C. Travaglio, R. Gallino, S. Amari, E. Zinner, S.E. Woosley, \& R.S. Lewis, Astrophys. J. 510 (1999) 325.

[8] P. Hoppe, R. Strebel, P. Eberhardt, S. Amari, \& R.S. Lewis, Meteoritics Planet. Sci. 35 (2000) 1157.

[9] T. Yoshida, H. Umeda, \& K. Nomoto, Astrophys. J. 631 (2005) 1039.

[10] T. Yoshida, Astrophys. J. 666 (2007) 1048.

[11] Z. Michalewicz, Genetic Algorithms + Data Structures = Evolution Programs 3rd rev. extended ed. (1996).

[12] S. Amari, P. Hoppe, E. Zinner, \& R.S. Lewis, Astrophys. J. 394 (1992) L43.

[13] T.K. Croat, T. Bernatowicz, S. Amari, S. Messenger, \& F.J. Stadermann, Geochim. Cosmochim. Acta 67 (2003) 4705.

[14] K. Lodders, Astrophys. J. 647 (2006) L37. 